\title{
Seroprevalence of Toxoplasma gondii in unmarried women in Qazvin, Islamic Republic of Iran
}

\author{
H. Jahani Hashemi' and M. Saraei ${ }^{2}$
}

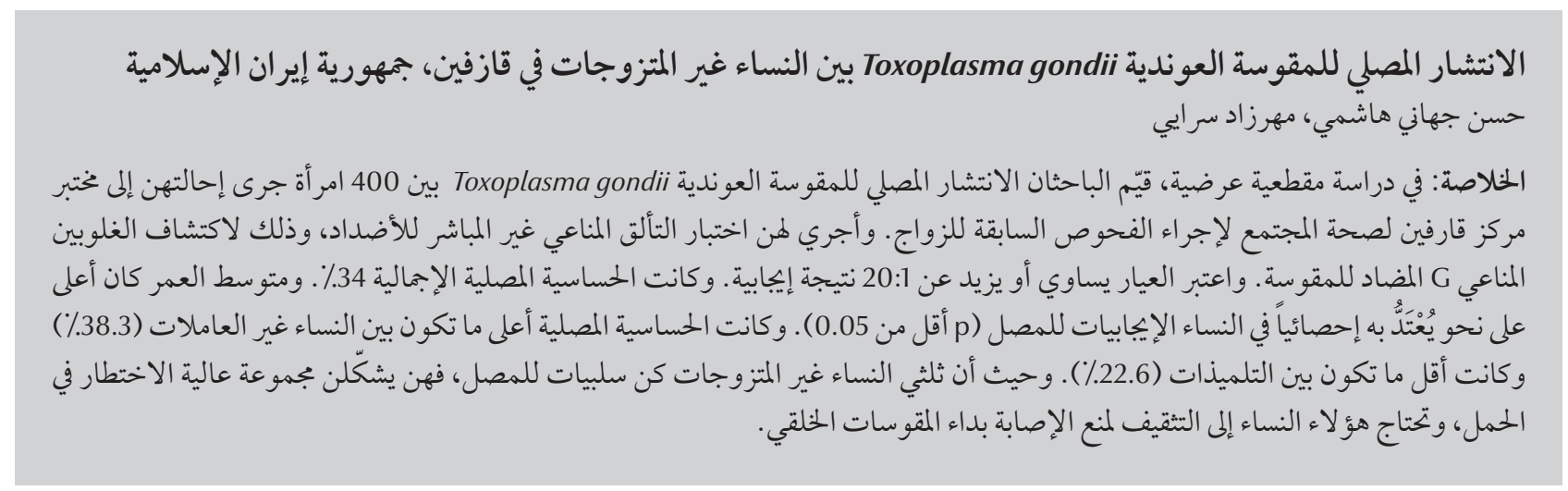

ABSTRACT In a cross-sectional study, we evaluated the seroprevalence of Toxoplasma gondii among 400 women referred to Qazvin community health centre laboratory for pre-marriage examinations. Indirect immunofluorescent antibody test was used to detect IgG anti-toxoplasma. Titres $\geq 1: 20$ were considered positive. The overall seropositivity was 34\%. Mean age was significantly higher in seropositive women $(P<0.05)$. Seropositivity was highest among unemployed women (38.3\%) and lowest among students (22.6\%), and was significantly higher in women with less than high-school education $(P<0.05)$. With two-thirds of these unmarried women seronegative, they represent a high-risk group in pregnancy. Such women need to be educated to prevent congenital toxoplasmosis.

\section{Séroprévalence de Toxoplasma gondii chez les femmes non mariées à Qazvin (République islamique d'Iran)}

RÉSUMÉ Dans une étude transversale, nous avons évalué la séroprévalence de Toxoplasma gondii chez 400 femmes adressées au laboratoire du centre de santé communautaire de Qazvin en vue d'examens prénuptiaux. La détection des anticorps anti-toxoplasmose de type IgG a été réalisée grâce à la technique de l'immunofluorescence indirecte. Les titres supérieurs ou égaux à 1/20 ont été considérés comme positifs. La séropositivité globale s'élevait à $34 \%$. L'âge moyen était significativement plus élevé chez les femmes séropositives $(P<0,05)$. La séropositivité la plus élevée se trouvait chez les femmes sans emploi $(38,3 \%)$ et la plus faible, chez les étudiantes $(22,6 \%)$; elle était significativement plus élevée chez les femmes qui avaient arrêté leur scolarité avant le secondaire $(P<0,05)$. Les deux tiers de ces femmes non mariées étant séronégatives, elles pourraient représenter un groupe à haut risque au moment de la grossesse. Une action éducative doit être menée auprès d'elles afin de leur éviter de contracter une toxoplasmose congénitale.

${ }^{7}$ Department of Community Medicine; ${ }^{2}$ Department. of Medical Parasitology and Mycology, Faculty ofMedicine, Qazvin University of Medical Sciences, Qazvin, Islamic Republic of Iran (Correspondence to H. Jahani Hashemi: jahanihashemi@qums.ac.ir; jahanihashemi@yahoo.com). Received: 21/02/07; accepted: 02/09/07 


\section{Introduction}

When seronegative women are infected with Toxoplasma gondii during pregnancy, the parasite may be congenitally acquired through the placenta. The rate of fetal transmission during first infection is $10 \%-25 \%$ in the first trimester, $30 \%-54 \%$ in the second and $60 \%-65 \%$ in the third [1]. Congenital toxoplasmosis can have serious consequences and may result in mental retardation, blindness and death [2].

Seroepidemiology of T. gondii has been reported in many countries. A high seroprevalence has been found in developed countries, such as France, where undercooked meat is commonly eaten [3], and in tropical areas where cats are abundant and the climate favours survival of oocysts [4].

In the Islamic Republic of Iran, at least 30\% of people are seropositive for T. gondii immunoglobulin $\mathrm{G}(\mathrm{IgG})$ in most regions, with the highest reported prevalences being in Gilan and Mazandran provinces (north of the country) $[5,6]$. Since seronegative pregnant women are at high risk for congenital toxoplasmosis, studies on T. gondii have focused on such women [7]. However, the ${ }^{\circ}$ re is no national programme for the prevention of congenital toxoplasmosis in the Islamic Republic of Iran.

The aim of this study was to conduct a toxoplasmosis serosurvey among premarriage women to provide data for an educational programme that will be designed to prevent $T$. gondii infection in women of childbearing age.

\section{Methods}

\section{Climatic conditions of the studied area}

The study was carried out in Qazvin province, which is located about $120 \mathrm{~km}$ north-west of Tehran. The average temperature is $24-27^{\circ} \mathrm{C}$ with a maximum of $40^{\circ} \mathrm{C}$ in summer and a minimum of $-10^{\circ} \mathrm{C}$ in winter. Rainfall varies from zero mm rainfall in August to 106.2 $\mathrm{mm}$ in December. The mean relative humidity is $16 \%-65 \%$ in summer and from $40 \%-86 \%$ in the winter.

\section{Sample size determination}

Using the formula:

$$
n=\frac{\left(Z_{\alpha / 2}+Z_{\beta}\right)^{2} P(1-P)}{d^{2}}
$$

where $\alpha=0.05, \beta=0.2, P=0.4, d=0.07$, the sample size was determined to be 384 , so 400 women who referred to the laboratory were selected.

\section{Subjects and collection of sera}

The 400 women were selected from those referring to the laboratory of the Qazvin community medicine centre between January and March 2004 for screening for thalassaemia prior to marriage (a requirement in the Islamic Republic of Iran). All the women who referred to the laboratory over this period were included in the study; there were no exclusions. The sera were kept at $-20^{\circ} \mathrm{C}$ until testing. The age range of the women was 13-39 years with a mean of 20 years (the legal age of marriage in the country is 18 years; for marriage under this age a court certificate is required).

Data on age, occupation and education of the women were obtained by interview questionnaire.

\section{Preparation of antigen}

The antigen was prepared according to the method of Goldman [8] used by Ghorbani et al. [5] using T. gondii RH strain. Smears with approximately 30-40 tachyzoites per power field of microscope $(x 400)$ were dropped on a glass slide and air dried (12 uniform thick smears). The slides were stored at $-20^{\circ} \mathrm{C}$ until testing and used as antigen.

\section{Immunofluorescence test}

The immunofluorescence test (IgGIFA) tests of sera samples were carried out according to the procedure used by Ghorbani, Edrissian and Assad [5]. Briefly, each serum sample was first examined at dilutions of $1: 20$ and 1:400; if the latter dilution gave a positive result, 2-fold serial dilutions were made in order to determine the end point. Fluorescein isothiocyanateconjugated rabbit anti-human IgG immunoglobulin (Daru Pakhash, Islamic Republic of Iran) was used at dilution of 1:50 in phosphate buffered saline with $1 \%$ Evans blue. The slides were examined under a Leitz fluorescence microscope, equipped with a Phillips CS 200 W-4 mercury lamp, and a combination of exciter filters BG12 and $B G 3$ and $570 \mathrm{~m} \mu$ barrier filter.

\section{Statistical analysis}

Statistical analysis was performed using chi-squared test, $t$-test and analysis of variance (ANOVA) with $P<0.05$ considered statistically significant.

\section{Results}

The overall, T. gondii seropositive rate (SPR) was 34\%. IgG titres < 1:20, $1: 20,1: 400,1: 800,1: 1600,1: 3200$ and 1:6400 were observed in $264(66 \%)$, 63 (15.8\%), 39 (9.8\%), 27 (6.8\%), 3 $(0.8 \%), 3(0.8 \%)$ and $1(0.3 \%)$ of the women respectively. $\operatorname{IgG}$ titres $\geq 1: 1600$ were observed in $1.9 \%$ of the women.

With regard to occupation, no significant difference in SPR was observed between unemployed women living with their families (38.3\%) and government employees (32.6\%), but SPR in students (22.6\%) was significantly lower than the unemployed women $(P<0.05)$ (Table 1). Mean ages of the unemployed women, government employees and students were 20 [standard deviation (SD) 0.6], 25.14 (SD 3.8) and 17.4 (SD 2.2) years respectively. Difference of mean ages was significant between the groups $(P<0.001)$ and, on post hoc comparison, this was due 


$\begin{aligned} & \text { Table 1 Distribution of IFA antibodies to Toxoplasma gondii in women referred for } \\
& \text { pre-marriage examinations according to occupation }\end{aligned}$
\begin{tabular}{|lccccccc} 
IgG $<$ 1:20 & \multicolumn{1}{l}{ IgG $\geq 1: 20$} & \multicolumn{2}{c}{ Total } \\
\hline Occupation & No. & $\%$ & No. & $\%$ & No. & $\%$ \\
\hline Unemployed out side the home & 153 & 61.7 & 95 & 38.3 & 248 & 100 \\
Government officer & 29 & 67.4 & 14 & 32.6 & 43 & 100 \\
Student & 48 & 77.4 & 14 & 22.6 & 62 & 100 \\
Other & 26 & 68.4 & 12 & 31.6 & 38 & 100 \\
Total & $256^{\text {a }}$ & 65.5 & $135^{\text {b }}$ & 34.5 & 391 & 100 \\
\hline
\end{tabular}

${ }^{a}$ With 8 missing; ${ }^{b}$ with 1 missing.

IFA = immunofluorescence.

to the student and government officer groups.

As shown in Table 2, SPR of T. gondii in women with less than high-school education was significantly higher than in women with higher education $(P<$ $0.05)$. The mean age of women with less than high-school education, highschool and higher than high school were 19.8 (SD 5.1), 20.6 (SD 2.9) and 23.1 (SD 3.7) years respectively. The difference in mean ages was significant between the 3 groups $(P<0.001)$ and, on post hoc comparison, this was due to subjects with higher than high-school education.

The SPR was not significantly different between urban and rural residents; SPR was $32 \%$ and $39.4 \%$ respectively. Mean age of urban residents was 20.7 (SD 4.1) years which was significantly higher than that of rural women [19.1 $(S D 4)]$ years $(P<0.001)$.

\section{Discussion}

In the presentstudy, 66\% of pre-marriage women were seronegative. This figure is very close to the Daryani and Saghar study [9] that reported $65.3 \%$ in same group in Ardabil (north-west of the Islamic Republic of Iran). Such women will usually become pregnant early in marriage in our country. Therefore, they are considered a high-risk group for congenital toxoplasmosis, if they seroconvert in the pregnancy period.
Traditionally, screening for toxoplasmosis has been carried out in France [3] and Austria [10] as a mandatory part of prenatal care. Prenatal screening has also been carried out in pilot projects in countries such as Finland [11], Sweden [12] and Brazil [13]. The screening programmes have revealed congenital toxoplasmosis prevalence values varying from 1 per 1000 [10] to 1 per 10000 [14] live births in Austria and the United States of America (Massachusetts) respectively. In the Islamic Republic of Iran, frequency of susceptible pregnant women in the first prenatal consultation (being seronegative) is not known. However, pregnant women at high risk of fetal transmission of toxoplasmosis at the beginning of pregnancy could be identified during this consultation.

It is generally accepted that the prevalence of antibodies in human populations depends on geographic, climatic, hygiene and socioeconomic conditions, as well as on the lifestyle of the population [15]. Studies have indicated that
IFA = immunofluorescence. the prevalence of $T$. gondii varies greatly in different areas of the Islamic Republic of Iran. The highest prevalence has been reported from Gilan and Mazandran provinces (in the north of the country) $[5,6]$ where the environmental conditions are more favourable for maturation and survival of oocysts than other regions. Qazvin is a southern neighbour of Gilan and Mazandran provinces and it is a region with moderate $T$. gondii seroprevalence in comparison to them.

In our study, mean ages of the seropositive women were significantly higher than the seronegative ones. Seroprevalence of $T$. gondii is known to increase by age $[2,15]$; we assume that the increase is a reflection of increasing exposure years of women to $T$. gondii. Infection with $T$. gondii starts with a short acute phase and proceeds to a latent phase when cysts are formed; these survive for the rest of the host's life, mainly in neural and muscular tissues. Data suggest that toxoplasma infection in humans is life-long, namely: there is a slow decrease in specific antibodies to T. gondii in an infected individual [16]; the frequency of seroconversion (loss of specific antibodies) among seropositive subjects is extremely low [17]; and there is a high frequency of reactivation of toxoplasmosis in seropositive AIDS patients [18]. IgG antibodies to T.gondii usually appear within 1 to 2 weeks of acquisition of the infection and peak within 1 to 2 month, then fall at variable rates, and usually persist for life [1].

Our results show that SPR in the unemployed women was significantly

\begin{tabular}{|c|c|c|c|c|c|c|}
\hline \multirow[t]{2}{*}{ Education } & \multicolumn{2}{|c|}{$\lg G<1: 20$} & \multicolumn{2}{|c|}{$\lg G \geq 1: 20$} & \multicolumn{2}{|c|}{ Total } \\
\hline & No. & $\%$ & No. & $\%$ & No. & $\%$ \\
\hline$<$ High school & 80 & 56.7 & 61 & 43.3 & 141 & 100 \\
\hline High school & 139 & 72.0 & 54 & 28.0 & 193 & 100 \\
\hline > High school & 45 & 68.2 & 21 & 31.8 & 66 & 100 \\
\hline Total & 264 & 66.0 & 136 & 34.0 & 400 & 100 \\
\hline
\end{tabular}


higher than students. The difference is probably due to age; mean ages of the unemployed women were significantly higher than the students. Toxoplasma prevalence in women with less than high-school education was significantly higher than in women with higher education. Lower levels of education are usually associated with lower socioeconomic status and may be related to employment in jobs with greater soil exposure. We found no significant difference in seroprevalence between urban and rural residents. Some studies showed higher $T$. gondii seropositivity among people who live in rural areas, but other studies have failed to show any difference [15,19-22].

Predicting future trends in T. gondii prevalence in the Islamic Republic of Iran is difficult because we do not have a national estimate of what proportion of $T$. gondii infections are attributable to undercooked meat exposure, cat faeces, soil or water exposure. Currently, there are no tests that can discriminate between oocyst ingestion and tissue cyst ingestion as the infection route. Considering the abundance of domestic and stray cats in the country, the consumption of uncooked vegetables and the suitable climatic conditions for sporulation of T. gondii oocysts, it seems that exposure to cat faeces is the principal route for Toxoplasma infection in the most parts of the country. Consumption of undercooked meat (kebabs) could be a second possible means for acquiring Toxoplasma infection in the area studied.

These data suggest that two-thirds of pre-marriage women in Qazvin are susceptible to acute toxoplasma infection. For this reason, it is important that women of childbearing age, especially pregnant women, be educated about the risk factors for $T$. gondii infection such as the danger of eating raw or undercooked meat, soil-related hygiene and handling of cats.

\section{Acknowledgements}

The authors would like to thank Dr H. Keshavarz, Professor of Parasitology, School of Health, Tehran University of Medical Sciences and Mrs S. Shojaei for kindly providing the RH strain. We also thank Mrs M. Damircheli for technical assistance and Dr GH-R. Dargahi for sera preparation.

\section{References}

1. Montoya JC, Remington JS. Toxoplasma gondii. In: Mandel GL, Bennett JE, Dolin R. Mandell, Douglas and Bennett's principles and practice of infectious diseases, 5th ed. Philadelphia, Churchill Livingston, 2000.

2. Jones JL et al. Toxoplasma gondii in the United States: Seroprevalence and risk factors. American journal of epidemiology, 2001, 154(4):357-65.

3. Baril $\mathrm{L}$ et al. Risk factors for Toxoplasma infection in pregnancy: a case-control study in France. Scandinavian journal of infectious diseases, 1999, 31(3):305-9.

4. Arias ML et al. Seroepidemiology of toxoplasmosis in humans: possible transmission routes in Costa Rica. Revista de biología tropical, 1996, 44(2A):377-81.

5. Ghorbani M, Edrissian GH, Assad N. Serological survey of toxoplasmosis in the northern part of Iran using indirect fluorescent antibody technique. Transactions of the Royal Society of Tropical Medicine and Hygiene, 1978, 72(4):369-71.

6. Assmar M et al. Toxoplasmose en Iran. Résultats d'une étude seroepidemiologique [Toxoplasmosis in Iran. Results of a seroepidemiological study]. Bulletin de la Société de pathologie exotique, 1997, 90(1):19-21.

7. Esmaeili Rastaghi AR, Assmar M, Nilforoshan MR. Prevalence of toxoplasma infection among the pregnant women and their newborn infants in Amol. Paper presented at the 4th National Iranian Congress of Parasitology, 13-16 October, 2003, Mashhad, Islamic Republic of Iran.

8. Goldman M. Staining Toxoplasma gondii with fluorescein labeled antibody. I. The reaction in smears of peritoneal exudates. Journal of experimental medicine, 1957, 105:549-56.

9. Daryani A, Sagha M. Seroepidemiology of toxoplasmosis in women referred to Ardabil laboratory of the health center for medical examinations before marriage, Iran, 2002. Paper presented at the 4th National Iranian Congress of Parasitology, 13-16 October, 2003, Mashhad, Islamic Republic of Iran.
10. Aspök H, Pollak A. Prevention of prenatal toxoplasmosis by serological screening of pregnant women in Austria. Scandinavian journal of infectious diseases. Supplementum, 1992, 84:32-8.

11. Lappalainen $M$, Koskela P, Hedman K. Incidence of primary toxoplasma infection during pregnancy in southern Finland: a prospective cohort study. Scandinavian journal of infectious diseases, 1992, 24:97-104.

12. Ahlfors $\mathrm{K}$ et al. Incidence of toxoplasmosis in pregnant women in the city of Malmö, Sweden. Scandinavian journal of infectious diseases, 1989, 21:315-21.

13. Neto EC et al. High prevalence of congenital toxoplasmosis in Brazil estimated in a 3-year prospective neonatal screening study. International journal of epidemiology, 2000, 29(5):941-7.

14. Eaton RB, Hsu H-W, Grady GF. Newborn screening for congenital toxoplasma infection. Paper presented at the 4th International Neonatal Screening Symposium, 13-16 June, 1999, Stockholm, Sweden.

15. Dubey JP, Beattie CP. Toxoplasmosis in man (Homo sapiens). In: Toxoplasmosis of animal animals and man. Boca Raton, Florida, CRC Press, 1988.

16. Konishi E. Annual change in immunoglobulin G and M antibody levels to Toxoplasma gondii in human sera. Microbiology and immunology, 1989, 33:403-11.

17. Kodym P et al. Toxoplasma in the Czech Republic 1923-1999: First case to widespread outbreak. International journal of parasitology, 2001, 31:125-32.

18. Garly ML et al. Toxoplasmosis in Danish AIDS patients. Scandinavian journal of infectious diseases, 1997, 29:597-600.

19. Studenicová C, Bencaiová G, Holková R. Seroprevalence of Toxoplasma gondii antibodies in a healthy population from Slovakia. European journal of internal medicine, 2006, 17(7):470-3.

20. Mohan B et al. Seroepidemiological study of toxoplasmosis in different sections of population of Union Territory of Chandigarh. Journal of communicable diseases, 2002, 34(1):15-22. 
21. Kawashima T et al. Prevalence of antibodies to Toxoplasma gondii among urban and rural residents in the Philippines. South-east Asian journal of tropical medicine and public health, 2000, 31(4):742-6.
22. Allain JP, Palmer CR, Pearson G. Epidemiological study of latent and recent infection by Toxoplasma gondii in pregnant women from a regional population in the UK. Journal of infection, 1998, 36(2):189-96

\section{Regional workshop on the implementation of best practices in family planning}

The World Health Organization (WHO) organized the Regional Workshop on the Implementation of Best Practices in Family Planning, in Amman, Jordan, from 27 to 30 September 2009

The objective of the Workshop is to build capacity in data collection and analysis. Experts from all countries of the Region, as well as from the United States and the United Kingdom, representatives of UNRWA, IPPF, UNFPA, UNICEF, USAID and the Population Council in Jordan, as well as WHO concerned staff, participated in the Workshop.

The Workshop covered, inter alia: Implementing best practices initiative for improving family planning; Reproductive health programme in the Eastern Mediterranean Region; Commodity security for ensuring sustainable family planning service delivery; Information, education and communication for promoting family planning practices; The ten elements of successful family planning; Mapping the implementation of best practices in family planning in the Eastern Mediterranean Region; Promoting family planning through community-based interventions; and Successful national family planning programme experiences in Egypt, Iran and Tunisia. 